\title{
A Review of 'Energy and Transport in Green Transition: Perspectives on Ecomodernity'
}

Published: 12 December 2016

Keywords: climate change; economy; energy; mitigation; modernity; transport

Energy and Transport in Green Transition: Perspectives on Ecomodernity

Atle Midttun and Nina Witoszek (Eds.)

Routledge: Oxford, UK. 2016

336 pp.; ISBN: 978-1138793439

Based both on scientific knowledge and the public opinion to end fossil fuels, political regimes seek more actively to substitute carbon-intense energy sources with greener and cleaner alternatives. However, each attempt to transition or transform energy production and consumption patterns towards more sustainable ends is bound to be affected by deep historical roots. As a result, both explaining and predicting energy development trajectories have proven to be a difficult task since they are deeply political, covering different social forces involved in the use, production and distribution of natural resources. The authors of "Energy and Transport in Green Transition-Perspectives on Ecomodernity" face this challenge when attempting to address the societally and scientifically crucial topic of energy and climate change mitigation.

This book begins with grand ambitions as the authors attempt "to go beyond both the extremism of the anti-capitalist critique and the radical enthusiasm of techno-economic positivism" in their investigation to find ways "to boost a greener economy and culture" by resolving political, economic and technological entanglements (p. 2). Their method of investigation comprises of a regional comparative study of mature Western economies, the rapidly developing China, and developing economies in sub-Saharan Africa. Importantly, editors Atle Midttun and Nina Witoszek frame their work on the "ongoing transformation" necessary to mitigate detrimental impacts on the climate as a "battle of modernities".
(Ch. 1) In this battle, each of the modernities come with their own myth, which all serve to mobilize the social world towards specific (technological) development trajectories. The authors construct a vision of the mitigation champion in the modernity brawl, namely their particular brand of "ecomodernity", which they argue is emerging and able to integrate the commercial, technological and, in particular, cultural visions within the ideas of green growth.

As this is it important for potential readers, let us first give room to how the authors construct their argument. The authors set off by decoding complex socio-economic green transitions occurring across the world. More specifically, the book covers two major themes: the history of energy sectors across four geographical regions, and more contemporary developments in the automotive industry. In this endeavour, the authors draw on neoclassical economic concepts and innovation studies as they target: the capability to drive innovation, the ability to mobilize public interest, and the challenges of staging complex pathways in a heterogeneous world with countries at different stages of development. The theoretical lineage that can be seen here makes reference to Schumpeter, and the book builds on "a multitude of international studies, reports, conferences and civil society initiatives" (p. 14), making reference to Daly, Max-Neef, Beck, Hajer, Dryzek, Jackson, and others.

Given the greater subject of sustainability and the grandness of the book's aspirations, it serves to articulate the authors' underpinning view on social change. Here, technological innovation and its diffusion play a central role-while also disregarding the actual possibility to drive green innovation at the level of Schumpeter's gale of creative destruction necessary to mitigate climate change (i.e. via industrial mutation destroy and replace an economic structure from within). Against this backdrop, the role of people and policy is posited as relational to three cycles: a product cycle, a visionary cycle, and an institutional cycle. Or in a charac- 
terization: as new green products and new societal visions develop, they may be successful enough to mobilize public intervention for more formalized and supporting institutions. It is in the interface between these three cycles that the authors place the dynamics of social change in "the battle of modernities". In particular, the interplay between the product- and the visionary cycle is given priority by the authors throughout the book. Subsequently, it is through this lens each chapter is to interpret empirical observations from across the world in order to theorize "in more detail the emergent vision of 'ecomodernity', which combines both technological, political, and cultural transformation" (p.14).

However, the challenge of drawing on so many, and vastly different, cases - historically, politically, institutionally, geographically, biophysically, sociologically etc.-while moving across such a long time span becomes apparent. Going back to the book's purpose, the analysis of empirical findings from each case is not sufficiently anchored in their theory. For example, the notion of mobilizing myths is only on rare occasions empirically rooted, and overall becomes reduced to ad-hoc arguments to fill gaps in the narrative. Thus, the authors do not provide the necessary depth to explain the dynamics of change involved in a truly convincing manner, even within their own paradigm. In defence of the authors, it is indicated in the Foreword that this is done to assure maximum accessibility, indicating that it is intended for a broader audience. The authors do present a very interesting descriptive exposé of various energy technologies and innovations of main concern for carbon emissions across time and space. However, the book's analytical forte becomes questionable as troublesome arguments emerge as, for example, institutions and organizations from conflict- ing social forces are viewed as part of the same cultural framing, working towards the same "ecomodernity".

Ultimately, the study object of the book becomes yet another story of energy technologies, and together with a hazy understanding, and analysis, of change, the authors reproduce the very techno-economic positivism they wanted to avoid. Despite this critique, the book presents worth-while descriptive historical reviews for those interested in the broader picture of energy production and the automobile sector in the regions addressed (i.e., the European Union, the United States of America, China, and sub-Saharan Africa). The overarching point of how the "ecomodernity" presented by the authors would consist of an interplay between the three cycles is made in a compelling manner, especially given rich level of detail presented in each chapter. Furthermore, the authors do not abstain from acknowledging the role the global economy may have played in technological development, especially in the case of photo-voltaics. Finally, I would recommend this book to readers interested in the data and the details, but not to those interested in deep academic discussions about economy and sustainability, and if/how a new champion may emerge from the battle of modernities.

\section{David Harnesk}

Lund University Centre for Sustainability Studies, and Lund University Centre of Excellence for the Integration of the Social and Natural Dimensions of Sustainability, Lund, Sweden; E-Mail: david.harnesk@lucsus.lu.se 